\title{
Do all Cases of Tumorectomy in Breast Cancer need Adjuvant treatments? About therapies in Encapsulated Papillary Carcinomas
}

\author{
Sedano P and Candini D* \\ Department of Radiation Oncology, Gregorio Marañón General University Hospital, Spain
}

Submission: May 31, 2018; Published: June 20, 2018

"Correspondence Address: Daniele Candini, Radiation Oncology Department, Gregorio Marañón General University Hospital, Calle del Dr. Esquerdo, 46, 28007, Madrid, Spain, Tel: +34 664732845; E-mail: danicandini@gmail.com

Abstract

Background: Intracystic papillary carcinoma (IPC), is an infrequent variant of non-invasive breast tumors, comprising only around $0.5 \%$ $1 \%$ of all mammary carcinomas. Even though it has a non-aggressive biological behaviour and a notable long-term prognosis, there is no general agreement in terms of therapeutic management, the tendency being to avoid adjuvant therapies such as radiotherapy.

Case Report: A caucasian woman of $75 \mathrm{yr}$, started with the appearance of a painless right breast node, with no other symptoms. Diagnostics confirmed a malignant node in the right breast, classified as BIRADS 4. The patient underwent a core needle biopsy and the histological study revealed a papillary neoplasia. The tumor board decided to perform lumpectomy and sentinel node biopsy with a final pathologic result of encapsulated papillary carcinoma, with positive hormone receptors, HER2 negative, Ki67=40\%, no lympho-vascular nor perineural invasion and negative sentinel lymph node. The patient was referred to radiation oncology department to evaluate adjuvant treatment. After reviewing the literature about pure IPC, with no in situ or intraductal component, no adjuvant therapies were performed. The patient was then referred to gynecology department for close follow-up. Nowadays, at 10 months follow-up she has a good performance status with no evidence of disease.

Keywords: Encapsulated Papillary Carcinoma; Adjuvant Treatment; Lumpectomy; Radiotherapy; Sentinel Node

\section{Introduction}

Intracystic papillary carcinoma (IPC) or better known nowadays as encapsulated papillary carcinoma, is an uncommon entity within non-invasive breast tumors, representing between $0.5 \%$ and $1 \%$ of all mammary carcinomas [1-4]. In the last WHO classification we can find the IPC divided in 4 subgroups: intraductal papilloma, intraductal papillary carcinoma, encapsulated papillary carcinoma and solid papillary carcinoma [5]. Over the last years this type of tumor has been found with other names too and has even been classified differently, however the fact that this type of disease has an indolent course and a good prognosis has remained consistent. Despite this last assertion, it is no completely exempt of the possibility of turning into a disseminated disease.

IPC is found more frequently among postmenopausal women, with a mean age around 67 years old, predominantly in caucasians [6-12]. The clinical presentation is variable, and it is possible to find asymptomatic patients, woman with a palpable node in an otherwise normal breast or even becoming manifest in the form of a swelling breast due to the presence of a large intracystic mass. Histologically, this tumor is usually described as an encysted lesion, containing nodules of papillary carcinoma surrounded by a thick fibrous capsule $[2,4,6]$. As in addition, and being more accurate with its histologic features, in the $4^{\text {th }}$ WHO classification, IPC was considered more as a less aggressive variant of papillary carcinoma, due to its lack of myoepithelial layer $[8,9]$. Regarding the radiological features, the tumor can be found in a mammographic image as a round, oval lesion or as a circumscribed lobulated mass (in consequence of the appearance of a dilated duct) [7-8].

Given the rarity of the disease and the lack of agreement in terms of histologic classification, there is no general consensus about the management of patients with this type of pathology. In spite of these inconsistencies, and taking into account its indolent course, the WHO working group recommends classifying them, and therefore managing them, as a Tis (in situ carcinomas), as long as they do not have clear invasive component $[5,9,13]$. Here we present the case of a woman diagnosed with pure IPC of the breast that is followed by a literature review focused on this subtype of papillary carcinoma with the aim of proposing a therapeutic management of these rare tumors.

\section{Case Report}

A pleasant caucasian woman of 75 yearsold, with hypertension and high colestherol as unique risk factors, consulted her 
primary care doctor, complaining about a painless right breast node, with no inflammatory signs. Clinical examination revealed a palpable mass, located on inferior-external quadrant (IEQ) of the right breast, mobile, of hard consistency and associated to skin retraction. A bilateral mammography showed a node in the periphery of IEQ of the right breast, suggestive of malignancy (BIRADS 4C).

Also a breast ultrasound was performed and described a hypoechogenic and discretely heterogeneous solid node with internal vascularization of $24 \times 13 \mathrm{~mm}$, lobulated margins and doubtful infiltration of the pectoral muscle. Both axillary areas were explored, with no apparent clinical suspicious nodes. The MRI of both breasts confirmed the existence of a suspicious image in the IEQ of the right breast, of around 2,2x1,1x1,5 cm (anteroposterior/transversal/cranio-caudal). No lymphadenopathies were identified. A core needle biopsy of such node was performed and it was informed as a papillary neoplasia with cytologic atypia, positive estrogen and progesterone receptors, HER2 negative and Ki67: 15\%.

Consequently to the findings of the study, the patient was presented at the breast tumor board where lumpectomy + sentinel lymph node biopsy were decided with final pathologic result of pure encapsulated papillary carcinoma, grade II, 17x12 $\mathrm{mm}$, with no lympho-vascular invasion nor perineural invasion. Clear surgical margins. Estrogen receptor: 100\%; progesteron receptor: 50\%; Ki67: 40\%; HER2 negative. Sentinel lymph node negative. TNM Stage: pTis pN0 cM0.

The patient was then moved to the radiation oncology department to consider the possibility of breast radiotherapy as adjuvant treatment. Given the rarity of the case and following review of the literature published on this histological subtype (pure intracystic papillary carcinoma, with no component of in situ nor intraductal carcinoma), mostly given by case reports or retrospective series, we concluded that this was a very noninvasive type of cancer where, in women over 50 years of age, no adjuvant therapies (radiotherapy and/or hormone therapy) may be indicated as it would not increase local control or the overall survival.
We spoke to the patient and family about this matter, and in consensus we reached the decision of therapeutic abstention and close follow-up by Gynecology department. At the last followup visit (10 months after diagnosis) no evidence of disease has been found.

\section{Discussion}

IPCs of the breast, are a subgroup of intraductal papillary lesions characterised by non-aggressive biological behaviour and excellent prognosis. However, there are few studies that discuss about its therapeutic management, having to consider that nowadays in this matter we can count on new treatment techniques that are less radical and aggressive such as sentinel lymph node biopsy or more conservative surgeries [9-11,14]. In addition, there is no agreement on the role of radiotherapy and hormone therapy in the management of pure IPC, nevertheless when this pattern is associated with an in situ or invasive component, there does seem to be a clearer consensus to treat it as a more aggressive tumor (adjuvant treatment with radiotherapy and/or hormone therapy). This lack of information is partly due to the fact that, being a disease of low incidence, the number of patients available for carrying out different studies is scarce. Also histological classification of these lesions is not clear and, as a consequence, staging and correct diagnosis of pure IPC can be controversial.

In the separation of papillary lesions into categories by Collins \& Schnitt [15] modified in the base of the WHO classification of tumors of the breast (2012), they clearly differentiate benign from malignant papillary lesions, and encapsulated from solid papillary carcinomas of the breast. IPCs are described as a lesion surrounded by a thick fibrous capsule and composed of delicate fibrovascular stalks; however, myoepithelial cells are not present, and their absence represents the most important criterion for differential diagnosis (Figure 1) [16]. Only a few clinical studies have been published on IPCs, most of them case reports. We reviewed the most important of these (Table 1), to help us reach the most reliable conclusions possible. The reported studies refer only to IPCs, not solid ones.

Table 1: Studies on the pure EPC of the breast: treatments and outcomes.

\begin{tabular}{|c|c|c|c|c|c|}
\hline Studies & $\begin{array}{c}\text { Patients } \\
\text { Analysed }\end{array}$ & $\begin{array}{c}\text { Mean Follow-up } \\
\text { (months) }\end{array}$ & LRR & DM & DSS (\%) \\
\hline Carter et al. [1] & 41 & 59 & $3 / 41$ & $0 / 41$ & $3 / 77$ \\
\hline Lefkowitz et al. [20] & 77 & 136 & $6 / 77$ & $1 / 29$ & 100 \\
\hline Leal et al. [12] & 29 & 42 & $1 / 29$ & $0 / 23$ & $1 / 46$ \\
\hline Harris et al. [10] & 23 & 52.5 & $1 / 23$ & $1 / 40$ & 100 \\
\hline Solorzano et al. [11] & 40 & 58 & $1 / 45$ & $0 / 5$ & 97.8 \\
\hline Fayanju et al. [9] & 45 & NR & $0 / 5$ & $0 / 14$ & 100 \\
\hline Seal et al. [13] & 5 & 20.8 & $0 / 14$ & $0 / 16$ & 100 \\
\hline Akagi et al. [21] & 14 & 14 & $1 / 16$ & & NR \\
\hline Calderaro et al. [22] & 20 & 38.2 & & & \\
\hline
\end{tabular}




\section{Cancer Therapy \& Oncology International Journal}

\begin{tabular}{|c|c|c|c|c|c|}
\hline Esposito et al. [14] & 27 & 37.5 & $2 / 17$ & $3 / 17$ & $1 / 38$ \\
\hline Wynveen et al. [23] & 38 & 72 & $1 / 38$ & $1 / 108$ & 100 \\
\hline Rakha et al. [8] & 108 & 53 & $7 / 108$ & $\mathbf{9 / 4 6 7}$ & 99 \\
\hline Total & $\mathbf{4 6 7}$ & $\mathbf{5 3}$ & $\mathbf{2 7 / 4 6 7}$ & $\mathbf{5 . 8 \%}$ & $\mathbf{9 9 . 4}$ \\
\hline
\end{tabular}

LRR: Loco-regional relapse; DM: Distant metastases; DSS: Disease-specific survival; NR: Not reported.

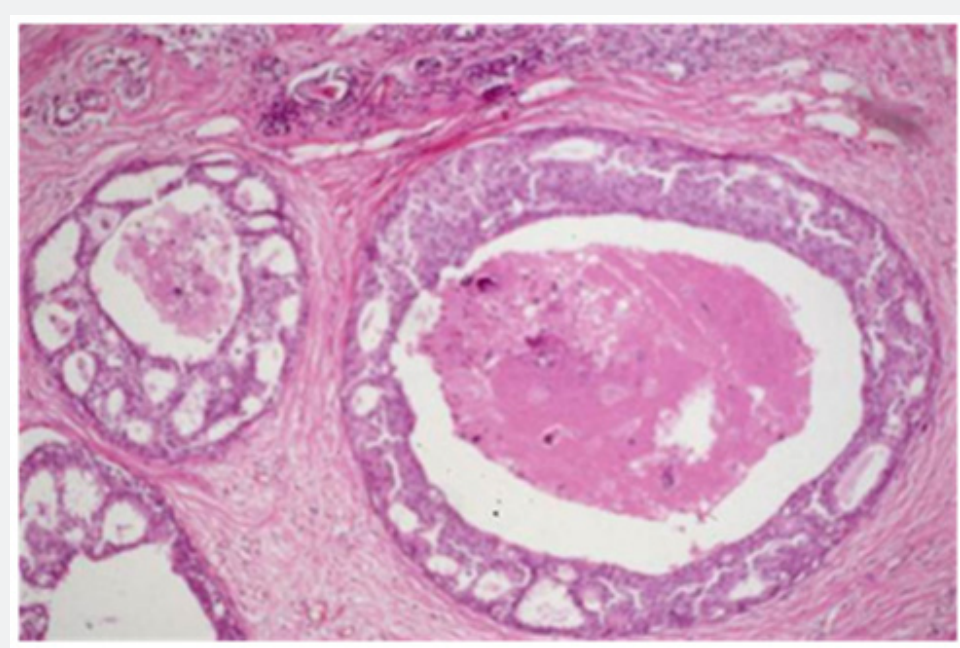

Figure 1: Encapsulated papillary carcinoma of the breast. An epithelial neoplasm with a papillary architecture delimited by cystic wall and absence of myoepithelial cells is observed.

As summarized at the end of Table 1 , in the last line, of a total of 467 patients with pure IPC only 27 (5.8\% of the total) had a loco-regional relapse and only 9 patients overall (1.9\%) suffered metastasis. Additionally, the percentage of survival related to the disease was $99.4 \%$. In particular, in the study by Solorzano et al. [11], no differences were found in the rate of local recurrence or death due to disease when analyzing the type of surgery (mastectomy or conservative surgery) or the associated use of adjuvant radiotherapy. They concluded that the decision about adjuvant therapy in these cases should be based on the presence of associated lesions, such as an in situ or invasive intraductal component, and that the benefit of radiotherapy in patients with pure IPC was unclear.

In another study performed by Fayanju et al. [9], after studying the data of 45 patients with IPC, the conclusion was that patients with pure IPC received less adjuvant therapies (radiotherapy and hormone therapy) compared to patients with IPC associated with an intraductal or invasive component. When clinicians have to decide about the therapeutic approach, patient age is also taken into account, with patients under 50 being more suitable for radiotherapy as compared to older ones. Another factor considered is the type of surgery performed, since the few patients who underwent a mastectomy did not receive adjuvant radiotherapy, but those who had undergone a more conservative surgery in some cases received adjuvant radiotherapy.

Despite this, it was found that no patient with pure IPC who had undergone a more conservative surgery had relapse due to it, corroborating what had been seen in other studies, that a mastectomy is not necessary in the treatment of pure IPC and that any adjuvant treatment should be tailored to patient's histology in order to ensure the excellent outcome expected for these neoplasms. Hence, adjuvant radiotherapy and/or hormone therapy should be considered both for patients with IPC associated with in situ component or microinvasion and for patients under 50 with pure IPC.

Esposito et al. [14], in their study of 27 patients suffering from IPC, confirmed that IPCs have an excellent prognosis and so local treatment alone may be sufficient to control the disease. Finally, in another retrospective study performed by Rakha et al. [8] with data from 207 patients with IPC, it was concluded that IPC is a carcinoma with a very favourable prognosis and that moderate local treatment, with an addition of hormone therapy in selected cases, is sufficient for an optimal outcome.

In general terms, many of these studies agreed to conclude that pure IPC variant has an indolent course with a very good prognosis even in those patients in whom the management is only surgical, without the association of adjuvant therapies. In addition, the absence of axillary lymph node involvement in this type of patients excludes the need to carry out axillary staging procedures [1,17-19]. However, some authors consider the procedure of sentinel lymph node biopsy as a prudent approach, given the uncertainty concerning the intraductal vs. invasive nature of IPC [20-23].

More recently, in 2016, a retrospective analysis was published, based on data from the SEER (Surveillance, 
Epidemiology, and End Results) database, including 2649 patients diagnosed with IPC [24], where the authors concluded that overall, IPC has a very good prognosis and that survival is improved in caucasian patients and in patients who receive radiation therapy, but two important limitations in this study were the inability to specifically assess whether patients had pure IPC or the presence of an invasive component and the fact that the effect of administration of other adjuvant therapies (such as hormone therapy) could not be assessed as these variables are not captured within the database.

\section{Conclusion}

In conclusion, it is well documented that IPCs have a completely non-aggressive biological behaviour and his prognosis is excellent if we are sure that IPC doesn't have invasive components or in situ carcinoma. Meticulous study, attention to morphology and correct interpretation of immunohistochemistry are imperative for accurate diagnosis of IPC. Consequently it is certainly possible to say that, if we are able to establish an accurate pathological diagnosis, with no misclassifications between pure IPC and other variants of more invasive papillary carcinomas (maybe histological features that can define invasion in papillary carcinomas should be better defined), we could treat IPC with simply a surgical extirpation assuring negative surgical margins (mainly lumpectomy and alternatively mastectomy for oversized tumors) and adjuvant therapies, such as hormone therapy and/or radiotherapy, could be safely avoided, although these therapies remains useful in the cases of young patients ( $<50$ years old) or which present either invasive elements or coexistent in situ carcinoma given their low, but not insignificant, possibility of locoregional relapse and/or distant metastases.

\section{References}

1. Carter D, Orr SL, Merino MJ (1983) Intracystic papillary carcinoma of the breast. After mastectomy, radiotherapy or excisional biopsy alone. Cancer 52(1): 14-19.

2. Czernobilsky B (1967) Intracystic carcinoma of the female breast. Surg Gynecol Obstet 124(1): 93-98.

3. Gatchell FG, Dockerty MB, Clagett OT (1958) Intracystic carcinoma of the breast. Surg Gynecol Obstet 106(3): 347-352.

4. Rosen PP, Oberman HA, Rosai J (1992) Tumors of the mammary gland. $3^{\text {rd }}($ edn), Armed Forces Institute of Pathology, Washington, DC, USA, pp. 209-219.

5. Lakhani S, Ellis I, Schnitt S (2012) WHO classification of tumors of the breast. Lyon: International Agency for Research on Cancer, Lyon, France.

6. Grabowski J, Salzstein SL, Sadler GR, Blair S (2008) Intracystic papillary carcinoma: a review of 917 cases. Cancer 113(5): 916-920.

7. Soo MS, Williford ME, Walsh R, RC Bentley (1995) Papillary carcinoma of the breast: imaging findings. Am J Roentgenol 164(2): 321-326.
8. Rakha EA, Gandhi N, Climent F, van Deurzen CH, Haider SA, et al. (2011) Encapsulated papillary carcinoma of the breast: an invasive tumor with excellent prognosis. Am J Surg Pathol 35(8): 1093-1103.

9. Fayanju OM, Ritter J, Gillanders WE, Eberlein TJ, Dietz JR, (2007) Therapeutic management of intracystic papillary carcinoma of the breast: the roles of radiation and endocrine therapy. Am J Surg 194(4): 497-500.

10. Harris KP, Faliakou EC, Exon DJ, Nasiri N, Sacks NP, et al. (1999) Treatment and outcome of intracystic papillary carcinoma of the breast. Br J Surg 86(10): 1274.

11. Solorzano CC, Middleton LP, Hunt KK, Mirza N, Meric F, et al. (2002) Treatment and outcome of patients with intracystic papillary carcinoma of the breast. Am J Surg 184(4): 364-368.

12. Leal C, Costa I, Fonseca D, Lopes P, Bento MJ, et al. (1998) Intracystic (encysted) papillary carcinoma of the breast: a clinical, pathological, and immunohistochemical study. Hum Pathol 29: 1097-1104.

13. Seal M, Wilson C, Naus GJ, Chia S, Bainbridge TC, et al. (2009) Encapsulated apocrine papillary carcinoma of the breast-a tumour of uncertain malignant potential: report of five cases. Virchows Arch. 455(6): 477-483.

14. Esposito NN, Dabbs DJ, Bhargava R (2009) Are encapsulated papillary carcinomas of the breast in situ or invasive? A basement membrane study of 27 cases. Am J Clin Pathol 131: 228-242.

15. Collins LC, Schnitt SJ (2008) Papillary lesions of the breast: Selected diagnostic and management issues. Histopathology 52(1): 20-29.

16. Collins L, O'Malley F, Visscher D, Moriya T, Ichihara S, et al. (2012) Encapsulated papillary carcinoma. In: Lakhani S, Ellis I, Schnitt S, Tan PH, van de Vijver MJ, editors. WHO classification of tumors of the breast. International Agency for Research on Cancer, Lyon, France, pp. 106-107.

17. Tavassoli FA (1999) Papillary lesions. In: Tavassoli FN (Ed), Pathology of the Breast. ( $2^{\text {nd }}$ edn), Stamford, CT: Appleton and Lange, USA, pp. 325-371.

18. Papotti M, Eusebi V, Gugliotta P, Bussolati G et al. (1983) Immunohistochemical analysis of benign and malignant papillary lesions of the breast. Am J Surg Pathol 7(5): 451-461.

19. Whitlock EP, Johnson RE, Vogt TM (1998) Recent patterns of hormone replacement therapy use in a large managed care organization. J Womens Health 7: 1017-1026.

20. Lefkowitz M, Lefkowitz W, Wargotz ES (1994) Intraductal (intracystic) papillary carcinoma of the breast and its variants: A clinicopathological study of 77 cases. Hum Pathol 25(8): 802-809.

21. Akagi T, Kinoshita T, Shien T, Hojo T, Akashi-Tanaka S, et al. (2009) Clinical and pathological features of intracystic papillary carcinoma of the breast. Surg Today 39(1): 5-8.

22. Calderaro J, Espie M, Duclos J, Giachetti S, Wehrer D, et al. (2009) Breast intracystic papillary carcinoma: An update. Breast J 15(6): 639-644.

23. Wynveen CA, Nehhozina T, Akram M, Hassan M, Norton L, et al. (2011) Intracystic papillary carcinoma of the breast: An in situ or invasive tumor? Results of immunohistochemical analysis and clinical followup. Am J Surg Pathol 35(1): 1-14.

24. Mogal H, Brown DR, Isom S, Griffith K, Howard-McNatt M (2016) Intracystic Papillary Carcinoma of the Breast: A SEER Database Analysis of Implications for Therapy. Breast 27: 87-92. 


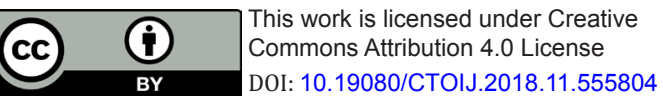

\section{Your next submission with Juniper Publishers will reach you the below assets}

- Quality Editorial service

- Swift Peer Review

- Reprints availability

- E-prints Service

- Manuscript Podcast for convenient understanding

- Global attainment for your research

- Manuscript accessibility in different formats ( Pdf, E-pub, Full Text, Audio)

- Unceasing customer service

Track the below URL for one-step submission https://juniperpublishers.com/online-submission.php 